\title{
PROGRAM KEMITRAAN MASYARAKAT WORKSHOP ENTREPRENEURSHIP MENUJU KEMANDIRIAN SISWA PONDOK PESANTREN AL-HAYATUL ISLAMIYAH DAN AL AZHAR KELURAHAN KEDUNGKANDANG KECAMATAN KEDUNGKANDANG KOTA MALANG
}

\author{
Wahyu Wiyani $^{1)}$, Budi Siswanto ${ }^{2)}$, Dewi Astutty Mochtar ${ }^{3)}$ \\ ${ }^{1,2)}$ Fakultas Ilmu Sosial dan Ilmu Politik Universitas Merdeka Malang \\ ${ }^{3)}$ Fakultas Ilmu Hukum, Universitas Merdeka Malang \\ email:wahyuwiyani86@yahoo.com
}

\begin{abstract}
Abstrak
Sebagai perwujudan kegiatan tridharma yang ketiga yakni pengabdian kepada masyarakat, tim melaksanakan kegiatan pengabdian di Pondok Al Hayatul Islamiyah dan Al Azhar, keduanya merupakan lembaga pendidikan yang mengemban misi membekali siswa ilmu agama, pengetahuan, dan ketrampilan. Bak gayung bersambut program kemitraan masyarakat workshop entrepreneurship ini sangat didukung oleh kedua sekolah, dimana peserta selain siswa juga beberapa guru ikut serta mendampingi.

Kegiatan pembentukan workshop entrepreneurship dilakukan dengan tujuan untuk memberikan ketrampilan dan memupuk jiwa wirausaha siswa, sehingga jika mereka telah lulus dan tidak melanjutkan pendidikan maka mereka sudah memiliki bekal ketrampilan dan kesiapan diri untuk berwirausaha. Adapun kegiatan yang dilakukan dalam program kemitraan masyarakat ini adalah: 1) Penyuluhan pentingnya pendidikan dan ketrampilan 2) Pelatihan Pembuatan Pudot (Pudding Sedot), 3) Pelatihan pembuatan kudapan lopis bihun 4) Pelatihan Pembuatan aneka keripik sayur, 5) Pelatihan Pembuatan aneka sirup, 6) Pelatihan kerajinan rajut, 7) Pelatihan kerajinan kain jumput, 8) Pelatihan kain pelangi, 9)Pelatihan kerajinan bunga dari botol plastik, 10) Pelatihan kerajinan kain perca. Untuk keberlanjutan kegiatan ini tim juga memberikan bantuan bibit nanas kepada kedua lembaga agar buahnya bisa dipergunakan untuk bahan pembuatan aneka sirup dan minuman segar serta daun bisa dipergunakan untuk bahan benang serat nanas sebagai bahan dasar kerajinan rajut.

Selain pelatihan dan pemberian bibit, tim juga memfasilitasi ruang pelatihan kewirausahaan dengan beberapa peralatan pendukung antara lain: 1) Lemari Es, 2) Mesin jahit, 3) Kompor gas, 4) blender, 5) Juicer, 6) Etalase, 7) Papan Nama, 8) Peralatan dapur, 9) aneka bahan pembuatan ketrampilan. Hasil dari pelatihan siswa telah mampu membuat aneka makanan dan minuman yang diajarkan serta membuat aneka produk ketrampilan berbahan kain dan kotol plastik, juga telah tersedia ruang workshop entrepreneurship yang dilengkapi peralatan pendukung.
\end{abstract}

Kata Kunci : Ketrampilan, Kemandirian, Workshop Entrepreneurship

\section{PENDAHULUAN}

Pondok pesantren merupakan pilihan pendidikan bagi masyarakat pedesaan yang sarat dengan kehidupan agamis, selain untuk menimba ilmu agama juga menimba ilmu umum sehingga lulusan pondok diharapkan nantinya tidak hanya pandai namun juga memiliki pegangan agama yang kuat. Pondok pesantren Al Hayatul Islamiyah dan AL Azhar merupakan dua pondok pesantren yang memiliki visi menjadikan anak didik memiliki akhlakul karimah juga kecerdasan yang tinggi dan terampil, sehingga nantinya setelah lulus diharapkan bisa mandiri baik secara jasmani maupun secara rohani.

Sesuai dengan amanah pendidikan bahwa sumberdaya manusia yang dihasilkan haruslah yang memiliki kompetensi untuk bisa mandiri dikemudian hari, karena kesuksesan suatu lembaga baik lembaga profit maupun non profit adalah keunggulan sumberdaya manusianya. Konsekuensinya, lembaga pendidikan formal seperti Sekolah Menengah Umum (SMU), Sekolah Menengah Kejuruan (SMK) dituntut untuk menghasilkan lulusan yang siap bekerja, memiliki sikap, watak dan perilaku wirausaha serta ketrampilan (life skill) untuk bekerja 
di segala bidang sesuai dengan kebutuhan dunia industri.

Untuk memberikan bekal tim berusaha memfasilitasi dengan berbagai kegiatan pelatihan dan beberapa peralatan penunjang agar nantinya kedua lembaga menghasilkan lulusan yang memiliki bekal ketrampilan untuk berwirausaha serta lembaga memiliki sumber pendanaan jika kegiatan ini bisa dikembangkan.Siswa kedua lembaga pendidikan tersebut masing masing memiliki passion yang berbeda terkait dengan ketrampilan, dan ini sangat sesuai dengan potensi wilayah masing masing, siswa Al Azhar lebih menyukai dan terampil dalam pembuatan olahan makanan dan minuman, ini sesuai dengan kondisi wilayahnya yang banyak menghasilkan sayur dan buah yang bisa diolah menjadi keripik dan aneka sari buah, sementara siswa El hayat lebih menyukai dan terampil dalam membuat aneka kerajinan tangan.

\section{METODE KEGIATAN}

Permasalahan yang dihadapi kedua mitra adalah tentang pendanaan untuk operasional sekolah yang minim, serta fasilitas untuk mengasah hardskill terutama ketrampilan siswa yang terbatas serta kurangnya kesadaran masyarakat akan pentingnya pendidikan.Solusi mengatasi masalah dengan memberikan penyuluhan tentang pentingnya pendidikan dan ketrampilan serta membentukworkshop entrepreneurship, workshop entrepreneurship merupakan inkubator yang dirancang untuk memberikan ketrampilan baik ketrampilan boga maupun ketrampilan kerajinan tangan dengan berbagai fasilitas pendukung berupa peralatan memasak dan peralatan kerajinan tangan serta etalase untuk mendisplay produk. Kegiatan seluruhnya dikelola oleh siswa dengan bimbingan guru artinya yang melakukan proses produksi, yang memasarkan produk, dan yang mengelola keuangan juga siswa. Untuk itu kegiatan pengabdian masyarakat Program Kemitraan Masyarakat Workshop Entrepreneurship di SMAI Al Azhar dan SMK El Hayat dilakukan dengan menggunakan tiga cara yakni: 1) Penyuluhan 2) Pemberian pelatihan dan 3) Pemberian Fasilitas Pendukung Workshop Entrepreneurship

\section{1) Penyuluhan}

Penyuluhan dilakukan kepada siswa dan orang tua untuk memberikan pemahaman kepada mereka tentang pentingnya pendidikan formal dan pendidikan informal berupa pelatihan ketrampilan untuk membekali siswa setelah lulus sekolah. Adanya penyuluhan ini diharapkan orang tua dan siswa sadar pentingnya pendidikan sehingga bisa mengurangi budaya pernikahan dini yang ada disana, serta sebagai modal ketrampilan untuk berwirausaha.

Kegiatan penyuluhan pentingnya pendidikan dan ketrampilan dilakukan di sekolah Al Azhar pada hari Sabtu, 17 Maret 2018 dengan jumlah peserta 17 orang..Dimana narasumber penyuluhan Drs. Priyo Darimolyo M.Si. Pada kesempatan ini disampaikan bahwa pendidikan bagi usia sekolah sangat penting apalagi diera global saat ini dimana tenaga dari manapun bebas keluar masuk ke Indonesia, kalau anak anak tidak mendapatkan bekal ilmu dan ketrampilan mereka akan kalah dan akan tetap berada di posisi bawah (buruh) yang relatif sangat rentan terhadap PHK karena ketrampilannya yang sangat minim. Selain itu adanya pendidikan yang memadai akan menghambat terjadinya pernikahan dini karena pengetahuan mereka yang semakin baik tentang kesehatan.

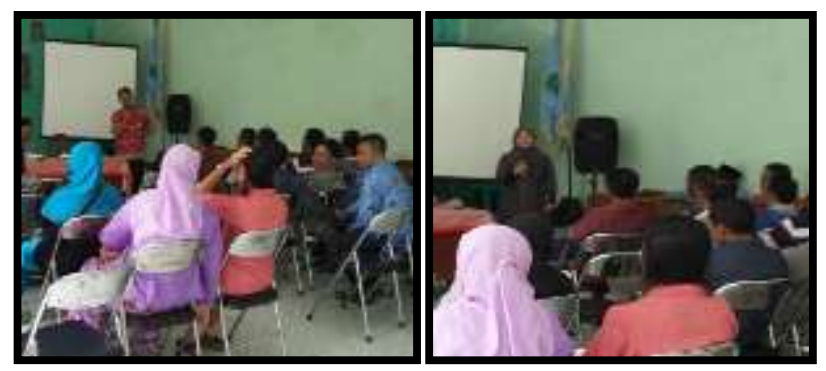

\section{2). Kegiatan Pelatihan ketrampilan}

Pelatihan ketrampilan selain sebagai modal bagi siswa untuk menjalani kehidupan selanjutnya juga bisa menjadi sarana pembentukan unit kegiatan siswa yang bisa menghasilkan uang untuk mendukung kegiatan sekolah.

\section{a. Pelatihan Ketrampilan di SMAI Al Azhar}

1). Pelatihan pembuatan aneka keripik sayurPelatihan dilakukan pada hari Jum'at 30 Maret 2018 pukul $07.00 \mathrm{~s} / \mathrm{d} 10.00$, diikuti 30 siswa dan tiga orang guru. 


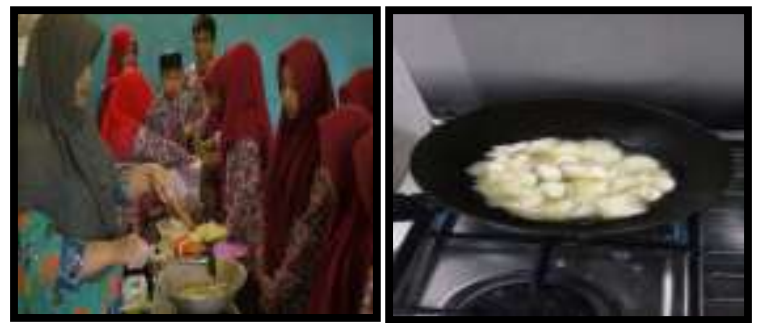

2) Pelatihan Pembuatan aneka sirup buah, Sabtu, 31 Maret 2018 pk 07.00 s/d 10.00, diikuti oleh 30 orang siswa
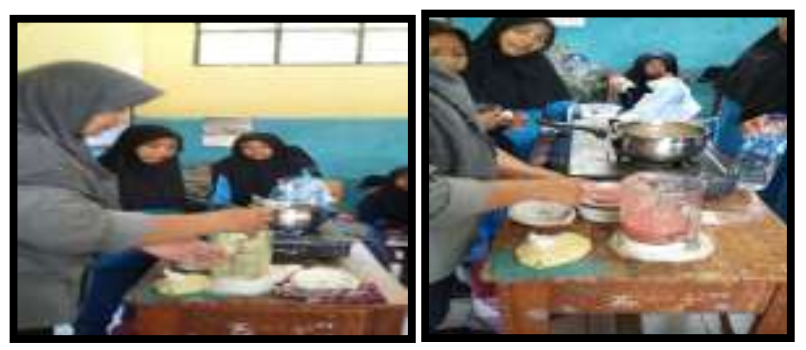

3) Pelatihan pembuatan bunga dari botol plastik, sabtu 7 april 2018, 07.00 s/d 11.00, diikuti 30 siswa
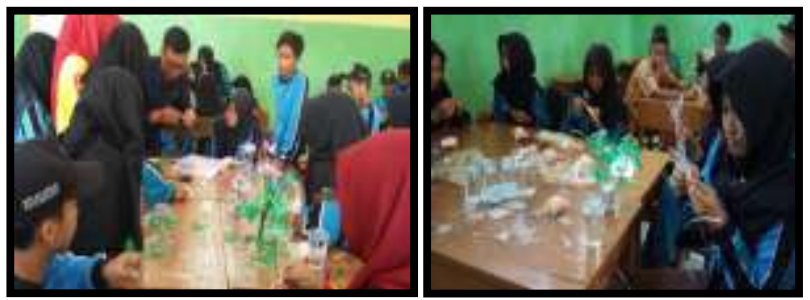

4) Pembuatan makanan pembuka puding sedot, Sabtu 5 Mei 2018, pk 07.00 s/d 10.00, diikuti 30 siswa
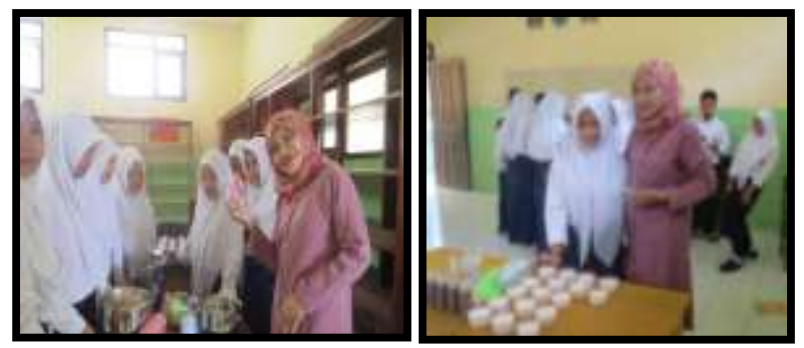

5) Pelatihan pembuatan aneka suvenir rajutSabtu 12 Mei 2018 pk 07.00 s/d 11.00, diikuti oleh 30 siswa

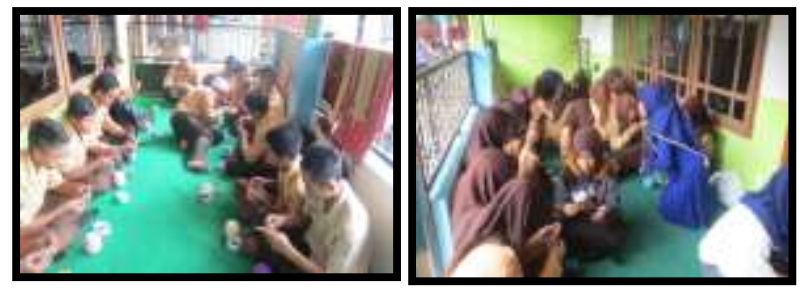

6) Pelatihan pembuatan batik pelangi Kamis, 28 Juni 2018, pk 07.00 s/d 11.00, diikuti oleh sejumlah 30 orang siswa
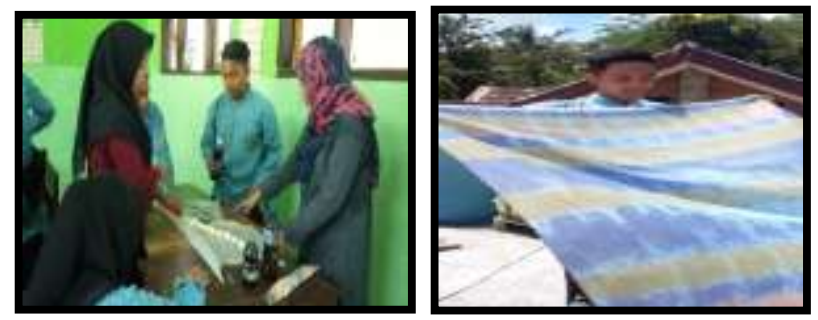

\section{Pelatihan Ketrampilan di El Hayat :}

1) Pelatihan pembuatan bunga dari botol plastik, diikuti 27 Orang siswa
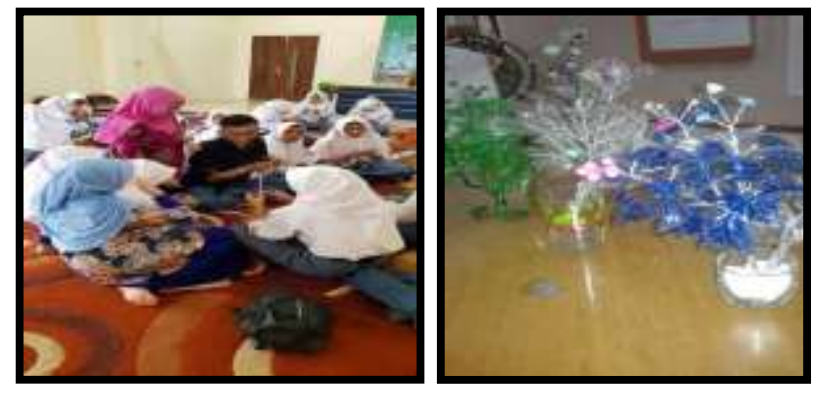

2) Pembuatan kerajinan kain perca, sabtu 21 April 2018, pkl 07.00 s/d 11.00, diikuti 27 orang siswa

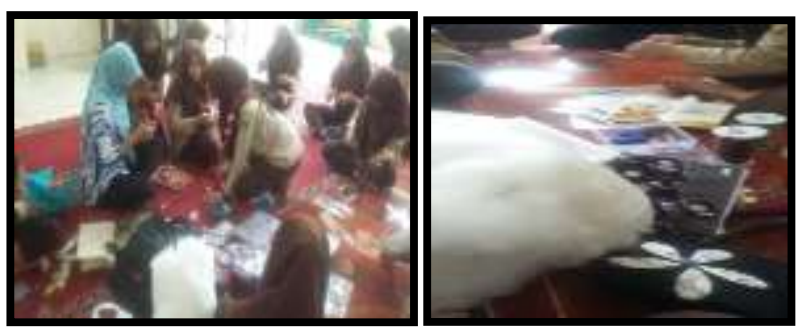

3) Pelatihan Pembuatan aneka produk rajut, senin 14 Mei 2018, pkl 07.00 s/d 11.00, diikuti 27 orang siswa

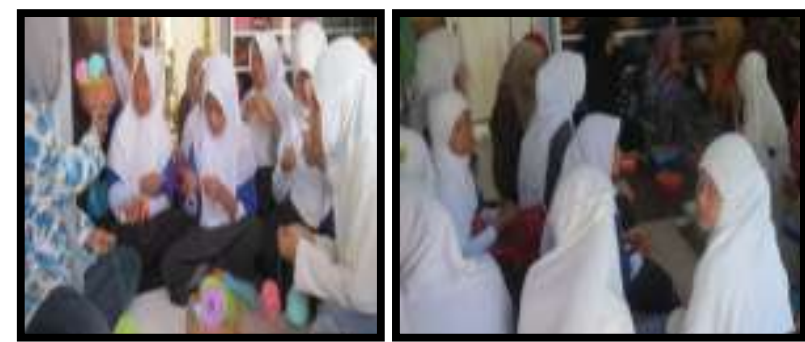

4) Pelatihan pembuatan kudapan lopis bihun Sabtu, 23 Juni 2018 pk 07.00 s/d 10.00, diikuti 27 orang siswa 


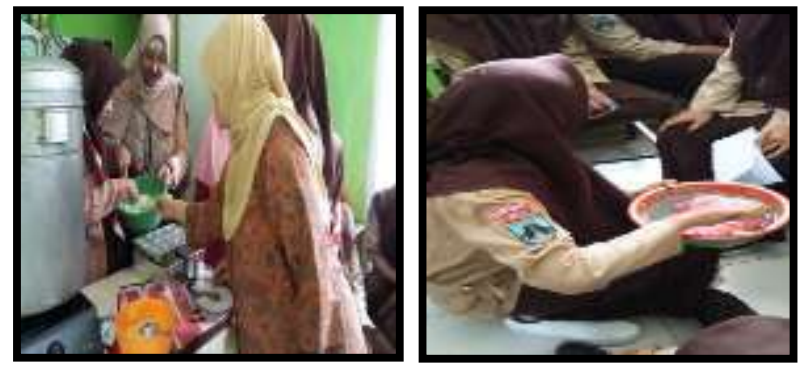

5) Pelatihan pembuatan kain jumput, Sabtu 30 Juni 2018, diikuti 27 orang siswa
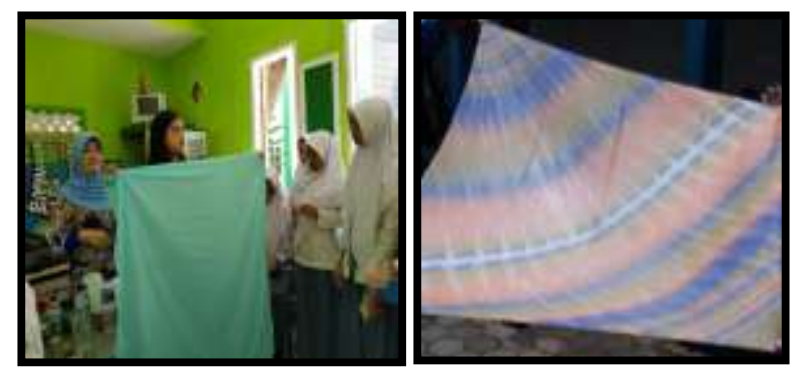

\section{Fasilitasi Workshop Entrepreneurship}

untuk menunjang kegiatan ketrampilan bagi siswa SMAI Al Azhar dan SMK El Hayat tim memberikan fasilitas sesuai dengan kebutuhan. SMAI Al Azhar siswa cenderung lebih menyukai memproduksi makanan dan minuman, sementara siswa SMK El Hayat lebih menyukai ketrampilan sehingga peralatan yang diberikan sedikit berbeda menyesuaikan dengan kebutuhan Fasilitasi Workshop Entrepreneurship,

\section{1) Fasilitasi untuk workshop entrepreneurship Al} Azhar

Sabtu 16 Juni 2018, bantuan Peralatan untuk SMAI Al Azhar : 1) Lemari Es, 2) Kompor gas, 3) Blender, 4) Mixer, 5) Oven, 6) Wajan, sendok, sutil, 7) Baskom Plastik 8) Panci, , dan 9) Peralatan dapur lainnya, 10) Papan nama, 11) etalase, 12) Bibit nanas, untuk pengembangan ketrampilan siswa dalam membuat sirup dan aneka minuman sari buah
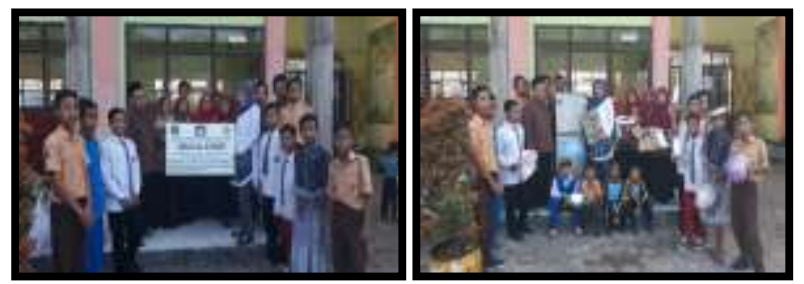

2) Fasilitasi untuk workshop entrepreneurship El Hayat

Sabtu, 16 Juni 2018. Bantuan peralatan untuk SMK El Hayat: 1) Mesin jahit, 2) Kompor gas 3) juicer 4)
Panci, 5) Baskom plastik, 6) Peralatan ketrampilan, 7) Bahan ketrampilan pembuatan bunga plastik, 8) Bahan ketrampilan kain jumput dan pelangi , 9) Bahan pembuatan ketrampilan kain perca, 10) Papan nama 10) etalase, 11) Bibit nanas untuk pengembangan ketrampilan rajut berbahan benang serat nanas,
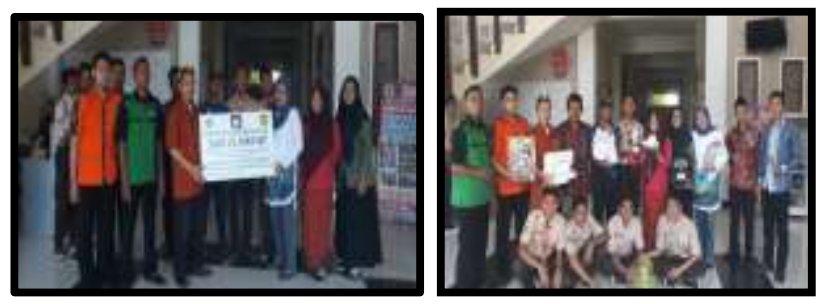

\section{HASIL DAN PEMBAHASAN}

Workshop entrepreneurship merupakan inkubator bagi siswa dalam upaya pengembangan kemandirian dan kewirausahaan mereka. Adanya workshop entrepreneurship diharapkan kemampuan siswa meningkat dalam menuangkan ide ide baru berbisnis serta mampu mengelola usaha mulai dari pengadaan barang/bahan, proses produksi, pemasaran sampai dengan pelaporan/ pertanggungjawaban keuangan.

Adanya workshop entrepreneurship berdampak positif bagi siswa dan sekolah antara lain: 1).Siswa memiliki ketrampilan memasak, 2) Siswa memiliki ketrampilan membuat kerajinan tangan, 3).Sekolah memiliki kepercayaan diri untuk mengikut sertakan hasil ketrampilan siswa dalam setiap kegiatan pertemuan sekolah, 4).Ada tambahan pemasukan bagi sekolah dengan adanya produk kreatif siswa yang dijual, 5). Tersedia fasilitas inkubator bagi siswa untuk melatih skill mereka dalam bidang keterampilan pembuatan aneka kuliner dan aneka kerajinan tangan.

Setelah mendapatkan pelatihan pembuatan aneka keripik siswa Al Azhar sudah mampu mempraktekkan membuat keripik bayam, keripik pare, keripik singkong, bahkan keripik daun singkong, untuk sirup buah siswa sudah mampu membuat sirup nanas, jambu, dan markisa dengan baik. Siswa El Hayat mampu membuat bunga dari bahan botol plastik dan beberapa hasil rajutan, aneka suvenir dari kain perca dan sudah mengikut sertakan hasil kerajinan siswa dalam pameran.. 
Hasil praktek pelatihan yang dilakukan siswa sebagai berikut:

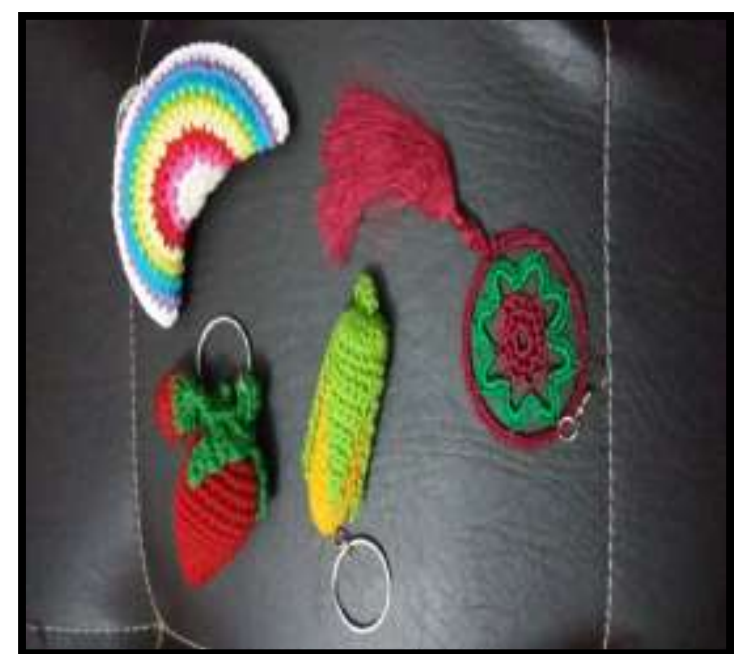

Hasil Pelatihan Rajut

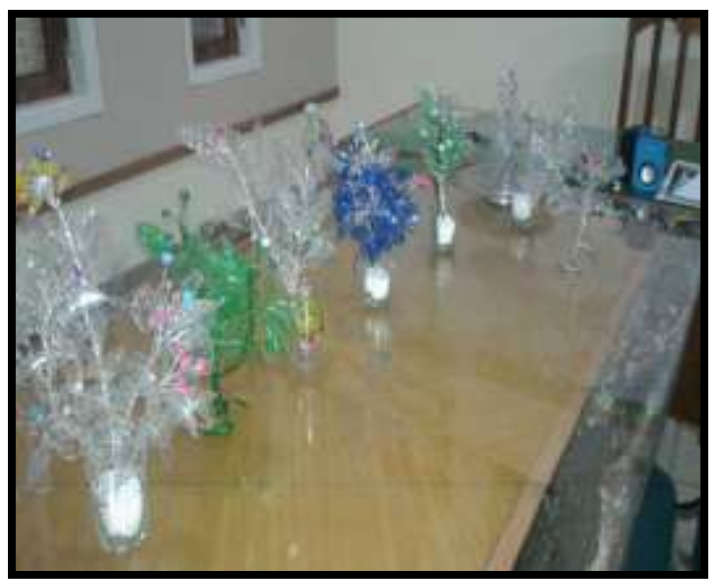

Hasil Pelatihan Bunga berbahan botol plastik

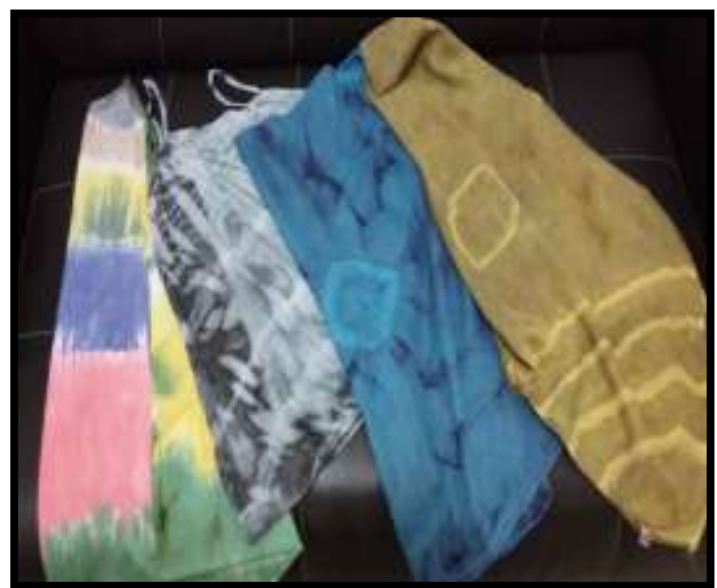

Hasil Pelatihan Kain Jumput \& batik Pelangi

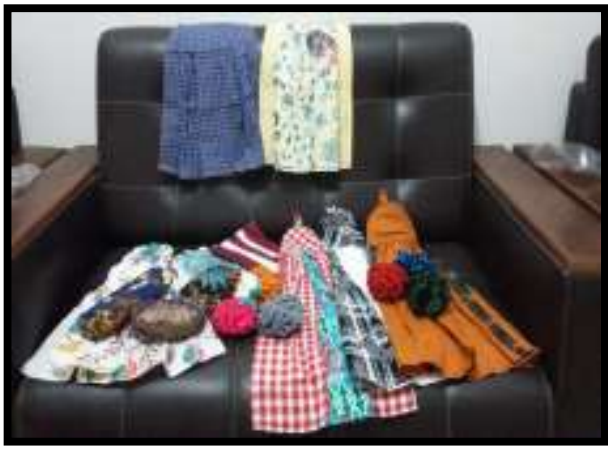

Hasil Pelatihan Kain Perca

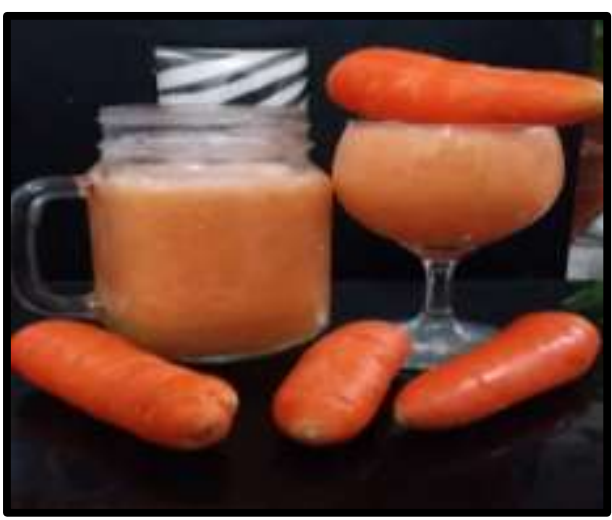

Hasil Pelatihan pembuatan sari buah

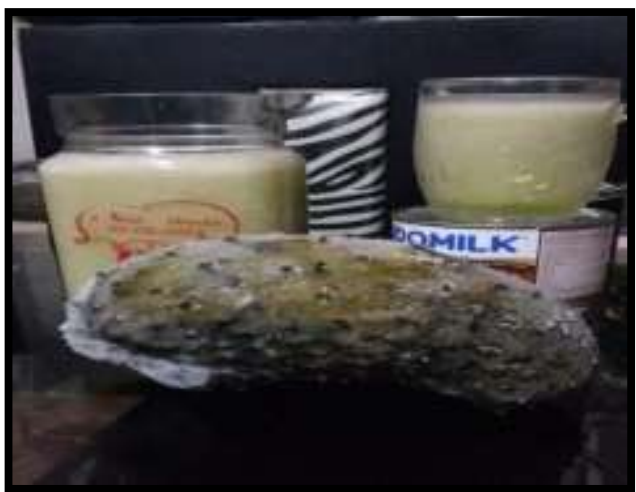

Hasil Pelatihan pembuatan sirup buah

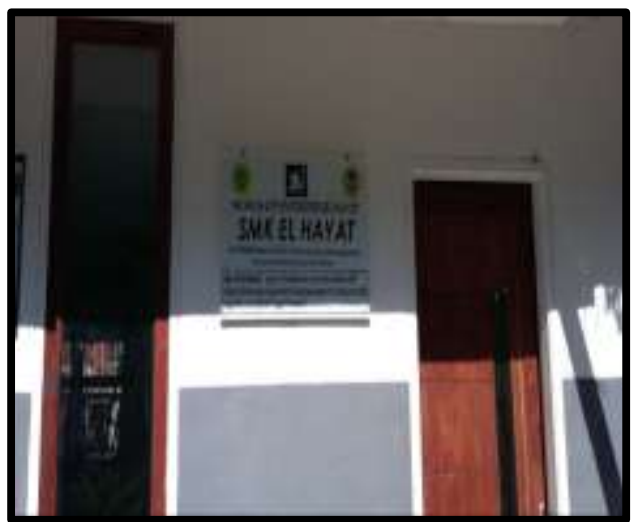

Ruang Workshop entrepreneurship 


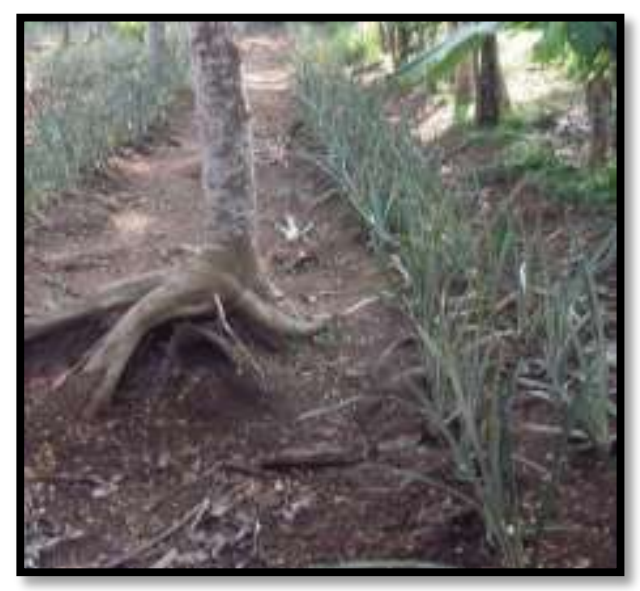

Bantuan Bibit Nanas

\section{KESIMPULAN DAN SARAN}

Dalam memberikan pelatihan terutama ketrampilan dari dua komunitas yang berbeda, tidak bisa kita menyamakan model pelatihannya, karena masing masing memiliki passion yang berbeda. Sama halnya dalam kegiatan yang tim lakukan, walaupun memiliki kesamaan dalam permasalahan namun pemecahan pemberian pelatihan sangat berbeda hasilnya. Awalnya ketrampilan yang kita berikan sama, namun setelah dua kali pelatihan terlihat bahwa tidak bisa kita memberikan solusi yang sama di dua komunitas yang berbeda, akhirnya pelatihan yang diberikan menjadi berbeda antara SMAI Al Azhar dengan SMK El Hayat.SMAI Al Azhar passion dalam ketrampilan memasak sementara SMK El Hayat lebih ke ketrampilan kerajinan tangan.

Dari hasil kegiatan beberapa saran yang bisa di sampaikan:

1) Pengelola sekolah Pondok Al Azhar dan El Hayat hendaknya mampu mengembangkan ketrampilan siswa setelah adanya fasilitas workshop entrepreneurship, sehingga setelah lulus siswanya bisa menjadi pelaku UMKM yang handal

2) Bagi pihak luar yang memiliki kelebihan baik dana maupun ketrampilan, mari kita baktikan ketrampilan dan dana yang kita miliki untuk membangun generasi muda kita agar lebih siap menjalankan kehidupan kedepan.

\section{REFERENSI}

http://cyberdakwah.com/2003/03/meneguhkankualitas-lulusan-pesantren/

https://www.researchgate.net/publication/26587 5366_MODEL_PENGEMBANGAN_KE WIRAUSAHAAN_SEKOLAH_MENENG AH_KEJURUAN_SMK_DALAM_MENC IPTAKAN_KEMANDIRIAN_SEKOLAH [accessed Apr 19 2018].

http://mooza-

alkaz.blogspot.co.id/2013/01/makalahkewirausahaan.html

http://catatanmakalah.blogspot.co.id/2015/03/m akalah-kewirausahaan-lengkap.html

http://detektiphoshiora.blogspot.co.id/2013/01/k ewirausahaan-dalam-pendidikan.html

http://pauluspinem.blogspot.co.id/2012/09/penti ngnya-kewirausahaan-dikalangan.html

http://arey-

teknologiinformasidankomunikasi.blogspot. co.id/2010/07/mengembangkan-jiwakewirausahaan.html

https://akhmadsudrajat.wordpress.com/2011/06/ 29/konsep-kewirausahaan-dan-pendidikankewirausahaan/

http://assetanita.blogspot.co.id/ 